\title{
LUXIÉRNAGA
}

Revista de Estudiantes de la Licenciatura en Filosofia de la UAA

\author{
Jennifer Patiño Aguilar
}




\section{Paradigma constructivista en la Educación}

\section{Introducción}

En este explicamos, a grandes rasgos, lo que es el Paradigma Constructivista, comenzamos por revisar los antecedentes y bases del mismo que están fundamentados en los estudios e investigaciones de Piaget, continuamos con las problemáticas y posturas del constructivismo, lo que da pie para el siguiente subtema que se refiere a los distintos tipos de constructivismo de los que contamos cuatro; Piagetiano, Humano, Social y Radical, cerramos con la forma en que el constructivismo aborda los componentes de la educación que son el alumno, maestro y la evaluación.

\section{Paradigma constructivista en la educación: Antecedentes y bases}

El constructivismo tiene sus raíces en la concepción de Piaget de una epistemología biológica, partiendo del supuesto de la existencia de una continuidad entre los diversos niveles de organización de la materia orgánica y el pensamiento.

Piaget basaba muchos de sus conocimientos en lo que era llamado la Escuela Nueva o Educación Nueva o activa que tuvo su epojé en Ginebra, La Escuela Nueva fue un movimiento educativo, tan interesante como a la vez complejo y amplio, desarrollado a partir de las décadas finales del siglo XIX e inicios del segundo milenio, esparcido sobre todo en Europa y Norteamérica. De los principios básicos, entre otros, compartidos por estas escuelas en el marco de la Escuela Nueva se destacan dos: el paidocentrismo y la búsqueda de la educación integral, términos de suma vigencia en la actualidad:

El mérito corresponde en gran parte a Edouard Claparède (I873-194o) y a Adolphe Ferrière (nacido en 1879). El segundo, a quien la lectura del libro de Demolins sobre los méritos de la educación anglosajona le descubrió su vocación, fundó en I899, en Ginebra, la Oficina Internacional de las Escuelas Nuevas, con fines de información y coordinación de las iniciativas 
en ese campo. La organización fue sustituida en 1925 por la Oficina Internacional de la Educación (BIE, o sea, Bureau International de l'éducation), cuya benemérita actividad es reconocida universalmente, al cuidado, además de Ferrière, de dos insignes psicólogos: Pierre Bovet, primero, y Jean Piaget, más tarde. ${ }^{\mathrm{I}}$

En esta llamada Nueva educación, centraban sus estudios en poner atención a la diferencia entre el niño/joven y el adulto, notaron que era muy diferente y que había que fortalecer el desarrollo del infante, ya que este pasaba por etapas que eran muy similares a las del desarrollo evolutivo del hombre a lo largo de todos estos años, además de que lo más importante en la educación nueva debía ser el 'interés':

La base de todo esfuerzo por aprender debe ser el interés, "piedra angular de la escuela activa", y, por último, la llamada ley biogenética por la cual el individuo en su evolución recapitula sintéticamente la evolución de la especie; sobre todo (como afirmara G. Stanley Hall) la evolución psicológica del niño repite las etapas de la evolución de la humanidad y las grandes épocas de la historia. ${ }^{2}$

Piaget, biólogo de formación, estudió ciencias naturales en la Universidad de Neuchâtel, mostrando posteriormente un particular interés por la Psicología, ciencia donde inicia sus trabajos sobre el desarrollo de las capacidades cognitivas. De ahí que se inclinase precisamente por los estudios de la psiquis para probar su tesis.

Los primeros estudios de Piaget estuvieron encaminados a elaborar un planteamiento de la génesis y desarrollo de las funciones psicológicas. Es por ello que la problemática central de su obra tiene un carácter epistémico, y se generaliza en la incógnita enunciada por el propio autor de cómo pasar de un cierto nivel de conocimiento a otro de mayor validez. Las investigaciones psicogenéticas y epistemológicas que se sucedieron a continuación dieron origen a la construcción y formalización del paradigma psicogenético piagetano.

Posterior a la segunda mitad de la década de 1930 se unen prestigiosos científicos a las investigaciones, entre los que resaltan B. Inhelder y A. Szeminska, además de equipos multidisciplinarios del Centro Internacional de Epistemología Genética de la Universidad de Ginebra. La teoría Psicoanalítica de Sigmund Freud explicaba el

\footnotetext{
${ }_{1}^{1}$ Abggano, Nicola, Historia de la pedagogía, Fondo de cultura económica, México, 1992, p. 461.

${ }^{2}$ Íbidem, p. 461.
} 
desarrollo psicosexual infantil y el Conductismo explicaba la mecánica del proceso de aprendizaje.

En la década de 1930 Jean Piaget afirmó que un niño no es 'un adulto en miniatura', idea que imperaba desde el siglo XVII, y sostuvo que el niño construye mediante la acción, es decir, que la acción es constitutiva de todo conocimiento. ${ }^{3}$

En lo sucesivo las aplicaciones e implicaciones del paradigma constructivista a la Pedagogía comenzaron a proliferar en relación al uso educativo de la teoría.

Ahora, la teoría de Piaget es una combinación de Biología, Epistemología y Psicología, que comprende una teoría ontogenética del desarrollo intelectual que conlleva a repercusiones en el campo de la Didáctica.

Muestran que, a partir de los primeros esquemas reflejos (succión, prensión, audición, visión, etc.), los niños pre-verbales evolucionan rumbo a esquemas adquiridos en función de la experiencia (hábitos), los cuales se coordinan entre ellos hasta alcanzar formas intencionales capaces de resolver activamente nuevos problemas prácticos. El aprendizaje alcanza un significado adaptativo en la medida en que expresa una acomodación activa por parte del sujeto y progresa, al buscar la novedad exterior, en función de las coordinaciones de los esquemas de inteligencia. ${ }^{4}$

La teoría del desarrollo cognitivo de Piaget es una teoría completa sobre la naturaleza y el desarrollo de la inteligencia humana primeramente desarrollada por el psicólogo del desarrollo. Se le conoce principalmente como una teoría de las etapas de desarrollo, pero de hecho, trata de la naturaleza del conocimiento mismo y cómo los seres humanos llegan gradualmente a adquirirlo, construirlo y utilizarlo. ${ }^{5}$

Piaget nos habla de una epistemología genética, entendiendo aquí la epistemología no como la ciencia que estudia a la ciencia, sino como la investigación de las capacidades cognitivas de un modo absolutamente empírico. Lo que sin duda, le diferencia también de la gnoseología; y en cuanto al uso del concepto genética este no se

3 Cfr. El enfoque constructivista de Piaget (en línea), Capitulo 5, pp. 267-268. http://www.ub.edu/dppsed/fvillar/principal/pdf/proyecto/cap_05_piaget.pdf

${ }^{4}$ Dongo M., Adrian, La teoría del aprendizaje de piaget y sus consecuencias para la praxis educativ, Revista IIPSI Facultad De Psicología, Universidad Estadual Paulista Campus De Marilia (Brasil), Vol.11, No. 1, 2008, p. 171.

${ }^{5}$ Cfr. Op. Cit. El enfoque constructivista de Piaget (en línea), 
refiere tanto al campo de la biología que estudia los genes sino a la investigación de la génesis del pensar en el humano.

Aunque Piaget, ciertamente, reconoce que tal génesis del pensar tiene en gran proporción de patrones que derivan de los genes, sin embargo, es uno de sus descubrimientos. Esta teoría constructivista, de Piaget, que está basada en el trabajo de Albert Bandura, quien menciona que los niños aprenden a comportarse tanto por medio de la instrucción, cómo los padres, maestros y otras autoridades y modelos les indican que deben comportarse, lo mismo que por medio de la observación, cómo ven que los adultos y sus pares se comportan. También, a los niños deben enseñárseles habilidades por medio de un proceso de instrucción, ensayo y retroalimentación, antes de hacerlo con una simple instrucción. Bandura hizo hincapié en que la auto eficiencia, definida como la confianza que el individuo tiene sobre sus propias habilidades para desempeñar diversas conductas, es importante para aprender y desarrollar comportamientos socialmente aceptados. Así, el desarrollo de habilidades no sólo se convierte en una cuestión de comportamiento externo, sino de cualidades internas. ${ }^{6}$

Esto conllevó una adecuación de la teoría que, en vez de utilizar las estructuras piagetianas de forma rígida, utilizase la metodología de una forma flexible que constituyese un marco de referencia en la aplicación de sus postulados.

Uno de los grandes aportes de Piaget a la Educación actual fue el de haber dejado fundamentado que en los primeros años de educación preescolar en el niño, el objetivo que se quiere es alcanzar el desarrollo cognitivo (aprendizaje). Y ello auspiciado y complementado por la familia, que ha enseñado y estimulado al niño, dándole a aprender algunas reglas y normas que le permitan asimilarse en un entorno escolar.

Otro aporte de Piaget que podemos ver reflejado hoy en día en las escuelas es que la teoría que se da en una clase, no basta para decir que el tema ha sido asimilado y

\footnotetext{
${ }^{6}$ Cfr. Dongo M., Adrian, La teoría del aprendizaje de piaget y sus consecuencias para la praxis educativ, Revista IIPSI Facultad De Psicología, Universidad Estadual Paulista Campus De Marilia (Brasil), Vol.11, No. 1, 2008, p. 167-181.
} 
aprendido, ya que el aprendizaje involucra métodos de pedagogía como lo son la aplicación de los conocimientos, la experimentación y la demostración.

La meta principal de la educación es crear hombres que sean capaces de hacer cosas nuevas, no simplemente de repetir lo que otras generaciones han hecho; hombres que sean creativos, inventores y descubridores. La segunda meta de la educación es la de formar mentes que sean críticas, que puedan verificar y no aceptar todo lo que se les ofrece. ${ }^{7}$

Con respecto al contenido de la cita de Piaget en la que se establece de manera explícita la meta de la educación en el ser humano y contrastado con la actualidad educativa, podemos observar que se puede estar dando en algunos aspectos educativos. Ello en razón de que hoy en día los niños(as) son capaces de transformar un conocimiento que se les presenta y construir nuevos aprendizajes, a partir de la guía que el maestro ha dado y también, en algunos casos, son capaces de cuestionar lo que aprenden a diario y de investigar, a la vez que tomar la iniciativa por su propia cuenta.

Otro aspecto dinamizado por Piaget, al igual que otros connotados pedagogos, para el desarrollo activo de la clase, es que los niños deben utilizar materiales y actividades para obtener los conocimientos que sean apropiados para su edad, teniendo en cuenta su capacidad mental y motriz; para así evitar pedirles a los alumnos que lleven a cabo tareas que van más allá de su desarrollo cognitivo, ${ }^{8}$ de lo que tenemos.

El aprendizaje al volverse más diferenciado y más libre de la asimilación inmediata contribuye para nuevas coordinaciones y nuevas reestructuraciones de la inteligencia. Sin embargo, es preciso decir, que mayor diferenciación y mayor independencia del aprendizaje no significa oposición o dicotomía entre éste y la inteligencia, como las teorías clásicas lo plantean. ${ }^{9}$

\section{Problemática y postura constructivista}

La problemática del paradigma constructivista es fundamentalmente epistémica. Desde sus primeros trabajos Piaget estuvo interesado en el tópico de la adquisición del

\footnotetext{
${ }^{7}$ Piaget, Jean, Psicología y Pedagogía, PSIKOLIBRO, p. 99.

8 Cfr. El enfoque constructivista de Piaget, Capitulo 5, pp. 300-302. http://www.ub.edu/dppsed/fvillar/principal/pdf/proyecto/cap_05_piaget.pdf

${ }_{9}$ Cfr. Dongo M., Adrian, La teoría del aprendizaje de piaget y sus consecuencias para la praxis educativ, Revista IIPSI Facultad De Psicología, Universidad Estadual Paulista Campus De Marilia (Brasil), Vol.11, No. 1, 2008, p. 172.
} 
conocimiento en su sentido epistemológico. ${ }^{10}$ Las preguntas básicas en que podemos traducir el espacio de problemas del paradigma son tres: ¿cómo conocemos? ¿cómo se traslada el sujeto de un estado de conocimientos inferior a otro de orden superior? ¿Cómo se originan las categorías básicas del pensamiento racional? por ejemplo, objeto, espacio, tiempo, causalidad, etc. Toda su obra está orientada en dar una respuesta original a esta problemática; una respuesta no especulativa como los filósofos anteriores a él lo habían hecho, con base en la introspección, la reflexión y la intuición, sino más bien una respuesta que debía ser científica e interdisciplinaria. ${ }^{\text {II }}$

A diferencia de las posturas empíricas que ven al sujeto como alguien que solo recibe el conocimiento, la problemática de los piagetianos otorga al sujeto un papel activo en el proceso del conocimiento. Suponen que la información que provee el medio, es importante, pero no suficiente para que el sujeto conozca. Por el contrario, y en acuerdo con los racionalistas, consideran que la información provista por los sentidos, está fuertemente condicionada por los marcos conceptuales que de hecho orientan todo el proceso de adquisición de los conocimientos.

Estos marcos conceptuales, no son producto de la experiencia sensorial, como podrían afirmarlo los empiristas, ${ }^{12}$ ni son innatos o a priori, como lo establecen algunos racionalistas, ${ }^{13}$ sino que son construidos por el sujeto cognoscente, cuando interactúa con los objetos físicos y sociales. El constructivismo piagetiano, a su vez, supone un tipo de realismo, dado que el sujeto no es el único responsable del proceso de construcción, como lo sostienen algunas posturas del constructivismo extremas, ${ }^{14}$ pero este realismo tampoco debe ser confundido con el realismo ingenuo de los empiristas.

\footnotetext{
${ }^{10}$ Cfr. El enfoque constructivista de Piaget, Capitulo 5, p. 275.

http://www.ub.edu/dppsed/fvillar/principal/pdf/proyecto/cap_05_piaget.pdf

${ }_{11}$ Confronte Lafuente Delgado, Xantale, Metodologías Innovadoras bajo el enfoque constructivista de la educación, Trabajo final de Master, 25 de junio de 2019, Valencia, p. 44.

${ }^{12}$ Blanco Scarlett, Sandoval Venecia, Teorías Constructivistas del aprendizaje, Tesis para obtener el grado en Licenciado en Educación, Universidad de Madrid, p. 33.

13 Ibid., p. 34.

${ }^{14}$ Blanco Scarlett, Sandoval Venecia, Teorías Constructivistas del aprendizaje, Tesis para obtener el grado en Licenciado en Educación, Universidad de Madrid, p. 55.
} 
Una categoría fundamental para la explicación de la construcción del conocimiento son las acciones, físicas y mentales, que realiza el sujeto cognoscente frente al objeto de conocimiento. Al mismo tiempo el objeto también actúa sobre el sujeto o responde a sus acciones, promoviendo en este cambio dentro de sus representaciones que tienen de él. Por tanto, existe una interacción recíproca entre el sujeto de conocimiento y el objeto. El sujeto transforma al objeto al actuar sobre él y al mismo tiempo estructura y transforma al objeto al actuar con él. El sujeto conoce cada vez más al objeto, en tanto se aproxima más a él, haciendo uso de sus instrumentos y conocimientos que posee, va creando una representación cada vez más acabada del objeto, ${ }^{15}$ pero al mismo tiempo, y en concordancia con el realismo del que estamos hablando, el objeto se aleja más del sujeto, el objeto se vuelve más complejo, planteándole nuevas problemáticas al sujeto, ${ }^{16}$ y nunca acaba por conocerlo completamente.

De igual modo, así como podemos decir que el sujeto epistémico, de la teoría piagetiana, es un constructor activo de conocimientos, debemos señalar que dichos conocimientos orientan sus acciones frente al objeto, en esto radica precisamente la noción de relativismo, el cual se refiere a que los objetos son conocidos en función de las capacidades cognitivas que posee en un momento determinado el sujeto cognoscente. Dicho de manera simple, el sujeto siempre conoce, en función de sus marcos asimilativos y en este sentido, se dice que se conoce lo que puede saber en un momento relativo de ese desarrollo. ${ }^{17}$ De igual manera se desprende de este y los párrafos anteriores, que nunca existe un nivel de conocimientos donde ya no se puede conocer más del objeto, sino que siempre se le puede conocer todavía más,

\footnotetext{
${ }^{15}$ Ortiz Granja, Doris, El constructivismo como teoría y métodos de enseñanza, Sophia, colección de filosofía de la educación, num. 19, Ecuador, 2015, p. 35.

16 Ibid., p. 36.

${ }^{17}$ Cfr. Blanco Scarlett, Sandoval Venecia, Teorías Constructivistas del aprendizaje, Tesis para obtener el grado en Licenciado en Educación, Universidad de Madrid, p. 56.
} 
cualquier nivel de conocimientos en un momento determinado, es simplemente un estado de equilibrio transitorio, abierto a niveles superiores de conocimientos. ${ }^{18}$

En la teoría del constructivismo aparece algo novedoso que, como tal, no está ni prefigurado en el objeto que se conoce ni en el propio sujeto conocedor. Lo construido es ciertamente influido por las interacciones entre lo uno, el objeto a ser conocido y lo otro, por ejemplo, los conocimientos previos que posee el sujeto; pero es cualitativamente una novedad: una reorganización, una reestructuración o una re descripción alternativa, que no se encuentra en su forma acabada en ninguna de las partes ya mencionadas y que, en gran medida, aparece como producto de la aplicación de la actividad constructiva del o de los sujetos cognoscentes, como consecuencia de una actividad organizadora.

En el fondo, a pesar de que no todos los constructivistas parecen compartir esta idea por igual, la sede de la genuina actividad constructiva parece residir en la intimidad del sujeto, aunque, como ya se ha dicho, incluso su origen pueda ser social. Empero, el constructivismo es una postura que no debe confundirse con el simple 'activismo'. Construir no es simplemente hacer, en el sentido de conducta observable; se puede realizar una importante actividad constructiva, aunque en apariencia se esté haciendo poco en el plano de la actividad manifiesta conductual y también puede realizarse escasa construcción del conocimiento aun cuando se realicen demasiadas actividades abiertas o públicas.

El que se señale que sea una construcción personal que ocurre de forma interna dentro del sujeto que conoce, no implica necesariamente que sea realizada "en solitario" porque aquél puede hacerlo en conjunción con otras personas ya sea presentes, con profesores, compañeros, etc., o distantes, con autores de textos, con otras personas interactuando en comunidades virtuales usando las TIC, etc., aunque la construcción, al final, tenga siempre un matiz propio como consecuencia de las características personales del sujeto.

\footnotetext{
${ }^{18}$ Cfr. Colona Manrique, Carmen Rosa y Rosa María Tafur Puente, El constructivismo y sus implicancias en educación, Educacion, Vol. VIII, no. 16, septiembre 1999, p. 220.
} 
Hay que tener presente que la actividad constructiva que realiza el sujeto variará en mayor o menor grado como en un continuo, dependiendo de la riqueza e involucración cognitiva con que se haga, así como de la aportación del contexto, especialmente del interpersonal y cultural, en donde ocurra. ${ }^{19}$

En conclusión, cuando se habla de constructivismo parece que se está hablando de una postura epistemológica en relación a cómo adquiere el conocimiento el ser humano; postura epistemológica que tiene como antagonistas principales al empirismo y para la cual el conocimiento se representa directamente en la mente del sujeto quien recibe pasivamente los estímulos del entorno, y al innatismo que sostiene que el conocimiento existe preformado de alguna forma en el sujeto y es hasta cierto punto independiente del medio externo. ${ }^{20}$

Entonces podemos decir, a forma de resumen que la postura constructivista tiene ciertas características y son las siguientes:

- $\quad$ El ambiente constructivista en el aprendizaje provee a las personas del contacto con múltiples representaciones de la realidad;

- Las múltiples representaciones de la realidad evaden las simplificaciones y representan la complejidad del mundo real;

- $\quad$ El aprendizaje constructivista se enfatiza al construir conocimiento dentro de la reproducción del mismo;

- El aprendizaje constructivista resalta tareas auténticas de una manera significativa en el contexto en lugar de instrucciones abstractas fuera del contexto;

- El aprendizaje constructivista proporciona entornos de aprendizaje como entornos de la vida diaria o casos basados en el aprendizaje en lugar de una secuencia predeterminada de instrucciones;

\footnotetext{
${ }^{19}$ Cfr. El enfoque constructivista de Piaget, Capitulo 5, p. 276.

${ }^{20}$ Cfr. Lafuente Delgado, Xantale, Metodologías Innovadoras bajo el enfoque constructivista de la educación, Trabajo final de Master, 25 de junio de 2019, Valencia, p. 33.
} 
- Los entornos de aprendizaje constructivista fomentan la reflexión en la experiencia; Los entornos de aprendizaje constructivista permiten el contexto y el contenido dependiente de la construcción del conocimiento;

- Los entornos de aprendizaje constructivista apoyan la construcción colaborativa del aprendizaje, a través de la negociación social, no de la competición entre los estudiantes para obtener apreciación y conocimiento.

\section{Tipos de constructivismo}

Como sucede con cualquier doctrina o teoría, el constructivismo alberga en su interior una variedad de escuelas y orientaciones que mantienen ciertas diferencias de enfoque y contenido.

El 'constructivismo piagetiano', ${ }^{21}$ que adopta su nombre de Jean Piaget, es el que sigue más de cerca las aportaciones de ese pedagogo, particularmente aquellas que tienen relación con la epistemología evolutiva, es decir, el conocimiento sobre la forma de construir el pensamiento de acuerdo con las etapas psico-evolutivas de los niños. En el campo de las teorías acerca de los procesos cognoscitivos, unas hacen referencia al carácter pasivo y otras al carácter activo de dichos procesos, como es el caso del constructivismo cognoscitivo defendido por Piaget. ${ }^{22}$ Este constructivismo sostiene que el niño construye su peculiar modo de pensar, de conocer, de un modo activo, como resultado de la interacción entre sus capacidades innatas y la exploración ambiental que realiza mediante el tratamiento de la información que recibe del entorno, de ahí la importancia de tener buenos modelos con los que interactuar.

Según los piagetianos la génesis mental puede representarse como un movimiento dialéctico de evolución en espiral, encontrándose en el centro de este proceso la actividad. Pero Piaget defiende una actividad organizada no una actividad arbitraria y sin sentido. Por tanto, la actividad será la constante de todo tipo de

${ }^{21}$ Cfr. Rosas Diaz, Ricardo. Piaget, Vigotski y Maturana: Constructivismo a tres voces, Aique grupo editor, Buenos Aires, 2008, p. 21.

${ }^{22}$ Cfr. Ídem. p. 19. 
aprendizaje desde el que tiene lugar en la etapa sensomotriz hasta el que culmina con las operaciones propias de las etapas lógico concreto y abstracto del pensamiento, en cuyas realizaciones va a desempeñar un papel fundamental al lenguaje, con esto nos referimos a que el alumno debe ser apoyado en todas las etapas de su crecimiento para lograr un desarrollo óptimo en el sentido biológico, racional y emocional. Piaget concede gran importancia también al conflicto cognitivo para provocar el aprendizaje. Los niños, y los adultos, progresan cuestionando los esquemas cognitivos con los que interpretan la realidad, al comprobar que ya no les resultan suficientes y generando la necesidad de cambiarlos. ${ }^{23}$ También son importantes en esta teoría la cooperación para el desarrollo de las estructuras cognitivas, intercambiando saberes, puntos de vista, opiniones, etc. porque la interacción entre compañeros suscita conflicto de opiniones; vincular aprendizaje con desarrollo perfectivo y la estrecha vinculación entre las dimensiones cognitiva y afectiva, resaltando la importancia en el aprendizaje, de la motivación.

Entonces la enseñanza basada en el aprendizaje constructivista pone énfasis en que los alumnos necesitan estar activamente implicados para reflexionar sobre su propio aprendizaje, realizar inferencias, transferencias y experimentar conflicto cognitivo. Esta conciencia de conflicto o dificultad, la comprobación de que el conocimiento de que uno dispone o su modo de trabajar es inadecuado, es un ejemplo de lo que los psicólogos llaman metacomprensión: el niño está preparado para saber cuándo se le hace saber que no sabe.

El constructivismo piagetiano tuvo un momento particularmente influyente durante las décadas de 1960 y 1970, impulsando numerosos proyectos de investigación e innovación educativa. Para Piaget, la idea de la asimilación es clave, ya que la nueva información que llega a una persona es "asimilada" en función de lo que previamente hubiera adquirido. Muchas veces se necesita luego una acomodación de lo aprendido, por lo que debe haber una transformación de los esquemas del pensamiento en función de las nuevas circunstancias. ${ }^{24}$

\footnotetext{
${ }^{23}$ Cfr. Ibid., p. 21

${ }^{24}$ Cfr. Ibid, p. 20.
} 
Por su parte, el 'constructivismo humano', ${ }^{25}$ surge de las aportaciones de Ausubel sobre el aprendizaje significativo, a los que se añaden las posteriores contribuciones neurobiológicas de Novak.

Novak apoya su teoría en la teoría del aprendizaje significativo desarrollada por Ausubel. ${ }^{26}$ En su teoría propone que construir significado implica pensar, sentir y actuar y que estos aspectos hay que integrarlos para construir un aprendizaje significativo diferente, sobre todo, para crear nuevos conocimientos. El aprendizaje significativo se da por medio de los conceptos, es a través de ellos que logramos entender y darle significado a la experiencia.

Novak, en esta teoría se refiere a cinco elementos de la educación esenciales a saber:

- $\quad$ El profesor: su actuación marca la diferencia entre un aprendizaje más significativo o uno más memorístico.

- El aprendiz: Es quién lleva a cabo una construcción del conocimiento en un proceso individual, facilitado por el profesor.

- $\quad$ El contexto: Está determinado por factores culturales y sociales que impactan directa o indirectamente en el proceso de aprendizaje.

- $\quad$ El conocimiento: debe ser altamente significativo, para ello, debe realizarse por medio de estrategias y materiales que les ayuden a los estudiantes a recuperar el conocimiento que tienen y tener relación con los intereses de los aprendices.

- La evaluación: para la evaluación se pueden utilizar herramientas que muestren el conocimiento que tienen los aprendices y de esta manera poder plasmar la forma en la que tienen organizado su conocimiento. Por ello, propone los mapas conceptuales como una poderosa herramienta en los procesos de evaluación del aprendizaje. ${ }^{27}$

En los puntos anteriores vemos que Novak demuestra como los conocimientos previos nos permiten crear conocimientos nuevos, a partir del conocimiento organizado, con la ayuda de estos mapas conceptuales, los que se componen de conceptos y preposiciones o incluso, creativamente, se pueden realizar con ilustraciones para aquellos que se inician en la escritura.

\footnotetext{
${ }^{25}$ Cfr. Lafuente Delgado, Xantale, Metodologías Innovadoras bajo el enfoque constructivista de la educación, Trabajo final de Master, 25 de junio de 2019, Valencia, p. 13.

${ }^{26}$ Cfr. Ibid, p. 15.

${ }^{27}$ Cfr. Ibid, p. 12.
} 
Otro tipo de constructivismo que es el 'constructivismo sociall ${ }^{28}$ se funda en la importancia de las ideas alternativas y del cambio conceptual, ${ }^{29}$ además de las teorías sobre el procesamiento de la información. Para esta versión del constructivismo son de gran importancia las interacciones sociales entre los que aprenden.

El constructivismo social es aquel modelo basado en el constructivismo, que dicta que el conocimiento, además de formarse a partir de las relaciones ambiente-yo, es la suma del factor entorno social a la ecuación: Los nuevos conocimientos se forman a partir de los propios esquemas de la persona producto de su realidad, y su comparación con los esquemas de los demás individuos que lo rodean. ${ }^{30}$

Como podemos ver el constructivismo social es una rama que parte del principio del constructivismo puro y el simple constructivismo, es una teoría que intenta explicar cuál es la naturaleza del conocimiento humano. Recordando que nuestro interés específico aquí no es explicar estas teorías constructivistas, sino sólo repasarlas para poder introducirnos en el tema de forma general.

Dentro de este tipo de constructivismo, que es el social, encontramos la Teoría Sociocultural de $V_{y g o t s k y}{ }^{31}$ que pone el acento en la participación proactiva de los menores, con el ambiente que les rodea, siendo el desarrollo cognoscitivo fruto de un proceso colaborativo. Lev Vigotsky ${ }^{32}$ sostenía que los niños desarrollan su aprendizaje mediante la interacción social: van adquiriendo nuevas y mejores habilidades cognoscitivas como proceso lógico de su inmersión a un modo de vida.

Para esta teoría aquellas actividades que se realizan de forma compartida permiten a los niños interiorizar las estructuras de pensamiento y comporta-mentales de la sociedad que les rodea, apropiándose de ellas. Repito que esto sólo es introductorio y no es de mi interés para este trabajo por lo tanto no aunare en el tema.

\footnotetext{
${ }^{28}$ Cfr. Rosas Diaz, Ricardo. Op. Cit, p. 45.

${ }^{29}$ Cfr. Ibid., p. 47.

${ }^{30}$ Cfr. Ibidem., p. 47.

${ }^{31}$ Cfr. Ibid, p. 50.

${ }^{32}$ Cfr. Ibid., p. 51.
} 
Finalmente, se ha denominado como 'constructivismo radical'33 a la corriente que rechaza la idea según la cual lo que se construye en la mente del que aprende es un reflejo de algo existente fuera de su pensamiento. En realidad, se trata de una concepción que niega la posibilidad de una transmisión de conocimientos del profesor al alumno, ya que ambos construyen estrictamente sus significados.

Para Von Glasersfeld, ${ }^{34}$ un constructivista radical, el término constructivismo radical se refiere a un enfoque no convencional hacia el problema del conocimiento y hacia el hecho de conocer. Éste se inicia en la presunción de que el conocimiento, sin importar cómo se defina, está en la mente de las personas, y que el sujeto cognoscente no tiene otra alternativa que construir lo que él o ella conoce sobre la base de su propia experiencia. El conocimiento entonces es construido a partir de las experiencias individuales. Todos los tipos de experiencia son esencialmente subjetivos, y aunque se puedan encontrar razones para creer que la experiencia de una persona puede ser similar a la de otra, no existe forma de saber si en realidad es la misma. ${ }^{35}$

Por lo tanto los constructivistas radicales entienden la construcción de saberes desde una vertiente darwinista y adaptativa, ${ }^{36}$ es decir, el proceso cognitivo tiene su razón de ser en la adaptación al medio y no en el descubrimiento de una realidad objetiva. A diferencia de los otros "constructivismos", en general calificables como "realistas", el constructivismo radical es idealista porque concibe el mundo como una construcción del pensamiento y, por tanto, depende de él.

\footnotetext{
${ }^{33}$ Cfr. Lafuente Delgado, Xantale, Metodologías Innovadoras bajo el enfoque constructivista de la educación, Trabajo final de Master, 25 de junio de 2019, Valencia, p. 18.

${ }^{34}$ Cfr. Ibid, p. 19.

${ }^{35}$ Cfr. Pimienta, Julio, Constructivismo: Estrategias para aprender a aprender, Person educación, México, 2008, p. 4.

${ }^{36}$ Cfr. Salzar, Ronnie, Pedagogía tradicional versus Pedagogía Constructivista, Guayaquil, 2 de octubre de 2013, p. 5.
} 


\section{Componentes generales}

Una vez que hemos revisado los antecedentes y los tipos de constructivismo parece que ya tenemos herramientas suficientes para pasar a analizar cómo se entienden dichos componentes generales en la educación, vistos desde el punto de vista del Constructivismo, claro está.

Siguiendo el mismo orden de ideas, y de acuerdo a todo lo expuesto anteriormente, el constructivismo tiene como fin que el estudiante, es decir el sujeto cognoscente, construya su propio aprendizaje, por lo tanto, A. Maya asegura que el maestro en su rol de mediador debe apoyar al educando para:

- Enseñarle a pensar: Desarrollar en el alumno un conjunto de habilidades cognitivas que les permitan optimizar sus procesos de razonamiento.

- Enseñarle sobre el pensar: Animar a los alumnos a tomar conciencia de sus propios procesos y estrategias mentales parar poder controlarlos y modificarlos, mejorando el rendimiento y la eficacia en el aprendizaje.

- Enseñarle sobre la base del pensar: Quiere decir incorporar objetivos de aprendizaje relativos a las habilidades cognitivas, dentro del currículo escolar. ${ }^{37}$

El papel del maestro desde la perspectiva constructivista, se orienta bajo la figura de guía y 'provocador' de situaciones de aprendizaje, en las que el participante dude de sus propias ideas y sienta la necesidad de buscar nuevas explicaciones, nuevos caminos que vuelvan a satisfacer esos esquemas mentales, los cuales, han sido configurados por la interacción con su medio natural y social. Scarlett Blanco comenta que el maestro desde este enfoque debe orientarse a:

- $\quad$ Parte de lo que el educando puede y lo alienta, lo escucha, orienta y motiva.

- Trabaja para la autoformación más que para corregir.

- Ofrece un equilibrio entre estímulo y autoridad.

- Motivar el respeto mutuo.

- El rol del profesor es ser un facilitador que guía al alumno a organizar y establecer relaciones de contenidos. Esto implica que el contenido debe ser relevante, novedoso, funcional y bien estructurado para que pueda ser memorizado y aprendido de manera comprensiva y no mecánica.

- Diagnostica permanentemente el estado emocional, el nivel cognoscitivo y los intereses del alumno.

${ }^{37}$ Maya, A. El taller educativo, Editorial Magisterio, 1996, p.112. 
- Usa terminología cognitiva tal como: Clasificar, analizar, predecir, crear, inferir, deducir, estimar, elaborar, pensar.

- $\quad$ Fortalece el razonamiento.

- Desafía la indagación haciendo preguntas que necesitan respuestas muy bien reflexionadas y desafía también a que se hagan preguntas entre ellos.

- Garantiza un continuo desafío, para que el niño, a partir de la desequilibración, construya nuevas estructuras intelectuales.

- Es promotor de la autonomía intelectual y moral de los alumnos.

- $\quad$ El profesor luego de facilitar puentes entre lo previo y lo nuevo, ofrece estructuras y estrategias que le permiten al alumno aprender de manera cada vez más autónoma, interactiva y bajo su propio control. ${ }^{38}$

Por otro lado, Blanco asegura que el rol del estudiante Constructivista debe considerarse como:

- $\quad$ Es un sujeto constructor activo de su propio conocimiento.

- Debe estar motivado y construye conocimiento al dar sentido a los conceptos a partir de su relación con estructuras cognoscitivas y experiencias previas. Es decir, que el alumno es responsable de su proceso de aprendizaje porque está en permanente actividad mental no solo cuando descubre y experimenta sino también cuando escucha al profesor.

- Se propicia la interacción entre alumno y profesor. Propone soluciones.

- Debe estar activo y comprometido. Aprende y participa proponiendo y defendiendo sus ideas.

- $\quad$ El aprendiz selecciona y transforma información, construye hipótesis y toma decisiones basándose en una estructura cognitiva.

- $\quad$ El sujeto posee estructuras mentales previas que se modifican a través del proceso de adaptación. ${ }^{39}$

Otro componente del constructivismo es la evaluación del aprendizaje del alumno. Los enfoques constructivistas orientan diferentes estrategias de evaluación. Privilegian el papel activo del alumno como creador de significado, la naturaleza autoorganizada y de evolución progresiva de las estructuras del conocimiento, es decir abordan la evaluación formativa. $^{40}$

La evaluación, por tanto, debe estar orientada a evaluar los procesos personales de construcción personal del conocimiento. La evaluación formativa ${ }^{41}$ se entiende como un

\footnotetext{
${ }^{38}$ Blanco Scarlett, Sandoval Venecia, Teorías Constructivistas del aprendizaje, Tesis para obtener el grado en Licenciado en Educación, Universidad, p.37.

${ }^{39}$ Ibid., p. 44.

${ }^{40}$ Cfr. Salzar, Ronnie, Op. Cit. p. 14.

${ }^{41}$ Cfr. Ibid., p. 25.
} 
refuerzo que ayuda al alumno a reconstruir el tema de evaluación y como parte del proceso generador de cambio que puede ser utilizado y dirigido a promover la construcción del conocimiento.

Los modelos utilizados tradicionalmente centran la evaluación en cogniciones aisladas sin considerar su conexión con el marco de conocimientos general y personal del alumno, esta tendencia a evaluar conocimientos como unidades ordenadas que se pueden aislar en forma artificial, no favorece la construcción del conocimiento que exige una evaluación que considere las cadenas complejas de significado y la interacción dinámica entre los mismos. ${ }^{42}$

Lo esencial en esta perspectiva es el concepto de integración ${ }^{43}$, es decir, propone que cualquier tipo de conocimiento puede ser entendido mejor en el contexto de un sistema de significados más amplio que lo apoye y relacione. La evaluación tradicional mide la cantidad de conocimientos u objetivos logrados, representados como la frecuencia de respuestas correctas en los instrumentos estructurados.

Las técnicas tradicionales se dirigen principalmente a evaluar el presente del alumno y en el mejor de los casos el pasado reciente, evaluación acumulativa, ${ }^{44}$ las técnicas constructivistas enfatizan la evaluación del desarrollo. La evaluación tradicional mide la cantidad de información memorizada por los alumnos. En el enfoque constructivista, se centra la atención en el nivel de análisis, por lo tanto, las capacidades del alumno para clasificar comparar y sistematizar son claves para la evaluación formativa. Esta forma de evaluación obtiene de los alumnos un conjunto de construcciones personales y únicas con las que estructuran su propio conocimiento, mientras que la evaluación tradicional sitúa a los alumnos en un conjunto de construcciones validadas externamente. ${ }^{45}$

${ }^{42}$ Cfr. Ortiz Granja, Doris, El constructivismo como teoría y métodos de enseñanza, Sophia, colección de filosofía de la educación, num. 19, Ecuador, 2015, p. 103.

${ }^{43}$ Cfr. Ibid, p. 104.

${ }^{44}$ Cfr. Ibid, p. 105.

${ }^{45}$ Abggano, Nicola, Historia de la pedagogía, Fondo de Cultura Económica, México, 1992, p. 464. 
La evaluación en este marco tiene la intención de dar a los estudiantes una oportunidad para seguir aprendiendo; esto exige que el profesor reconozca las diferencias individuales y de desarrollo de intereses, capacidades, destrezas, habilidades y actitudes. ${ }^{46}$ Así, la evaluación debe partir verificando lo que los alumnos ya saben. La evaluación constructivista mide:

- Los conocimientos adquiridos y la capacidad de los alumnos para aplicarlos en situaciones variadas.

- $\quad$ El desarrollo de destreza, habilidades y cambio de actitudes.

- Si los alumnos son capaces de establecer una relación con el conocimiento que difiere de la que demanda el profesor.

- $\quad$ Si los alumnos contribuyen a aportar un nuevo significado al conocimiento, alterando incluso la dinámica de la interacción establecida por el docente en el aula.

- La validez de construcción debe verificar si se está evaluando lo que realmente se espera que los alumnos construyan, lo que implica una clara definición de capacidades; una declaración explícita de las normas, que deben ser justas para los alumnos; una clara definición de criterios de evaluación, cuando será considerada una construcción buena, mala o regular; e instrucciones comprensibles para la comunicación de los aprendizajes. ${ }^{47}$

\section{Conclusiones}

Son tres las conclusiones a las que podemos llegar:

La primera es que el alumno es protagonista de su propio aprendizaje. El alumno identifica si ha de interesarle o no el contenido y si lo haya significativo, pertinente y no arbitrario, en comparación de su esquema previo, y quien debe estar más atento a su proceso de aprendizaje.

La segunda conclusión es que el sujeto no es una isla, está inmerso en una situación social, o más bien, varias situaciones sociales, que influencian su auto-imagen y potencial de aprendizaje por medio de esfuerzos directivos, o simplemente por el hecho de que ya existen relaciones de conocimientos previamente construidos a los que recientemente llega a tener acceso, por tanto, no se pueden desligar de los procesos cognitivos los procesos emocionales del aprendizaje.

\footnotetext{
${ }^{46}$ Pimienta, Julio. Constructivismo: Estrategias para aprender a aprender, Person educación, México, 2008, p. 6.

${ }^{47}$ Salzar, Ronnie. Op. Cit, p. 17.
} 
La tercera conclusión es que depende del grado en que se conjugan, alumno profesor y contenidos, para poder arribar a un aprendizaje exitoso, y no solamente de la simple comprensión del alumno mismo. 